\title{
Effect of the Adhesive Strength on the Bendability of Vibration-damping Composite Steel Sheet*
}

\author{
By Yoshihiro MATSUMOTO, ,* Masatoshi SHINOZAKI,** \\ Kozo TSUNOYAMA ${ }^{* *}$ and Hiroshi TSUNEKAWA**
}

\section{Synopsis}

Effect of adhesion strength on the bendability was studied in a compositetype vibration-damping steel sheet which consists of two steel skins bonded with a viscoelastic resin. The adhesion strength of the damping sheet was evaluated in tensile shear strength (TSS); TSS values of the damping sheets used for the test were $6,61,126$ and $148 \mathrm{kgf} / \mathrm{cm}^{2} . U$ - and 90 deg-bend tests were adopted as bend formability tests.

It was found that the bendability of the damping sheet is closely related to their TSS, and it is improved with an increase of TSS. When the TSS is higher than $126 \mathrm{~kg} / \mathrm{cm} \mathrm{cm}^{2}$, the bendability of the damping sheet is quite similar to that of conventional steels. On the other hand, when the TSS is as low as $6 \mathrm{~kg} f / \mathrm{cm}^{2}$, the slip and peel-off between two skins were observed in the bend tests.

In the 90 deg-bend test, the damping sheet with TSS of lower than 61 $\mathrm{kg} f / \mathrm{cm}^{2}$ bend properties are different from the conventional steel. In large size of bend radius, bend angles of the damping sheet were larger than those of the conventional steel. However, in small size of bend radius, bend angles of the damping sheet were smaller than those of the conventional steel. These behaviors of the damping sheet are based by elastic property of the core resin.

\section{Introduction}

A vibration-damping composite steel sheet is composed of two skin steel sheets and a thin visco-elastic material (Fig. 1). The damping steel sheet has a high damping quality and good formability. Therefore, the damping steel sheets have been applied to oilpans for large size diesel-engine trucks since several years ago. However, bend forming is very difficult for the damping steel sheet. The discrepancy or peel-off between the skin steel and core resin often occurs after the bend forming. In this paper, the effect of adhesive strength on the bendability in the damping steel sheet is discussed.

\section{Experimental Method}

An extra low carbon and extra deep drawing quality steel sheet was used for the skin steel sheet. A binding agent of butyral type resin was used for the visco-elastic material. After the resin was blended with a plasticizer, $0.1 \mathrm{~mm}$ thick films were made from the mixture by using a T-die film forming machine. Since the adhesive strength is closely concerned with the damping quality, the tensile shear strength (TSS)

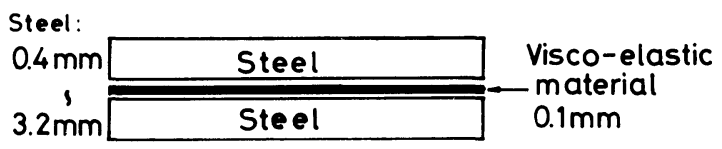

Fig. 1. Configuration of a vibration-damping composite steel sheet. is changed in damping qualities of visco-elastic materials. ${ }^{1)}$ Measurement of TSS was submitted to JIS $\mathrm{K} 6850$, and the damping qualities were evaluated by loss factors $\left(Q^{-1}\right)$ using the mechanical impedance method.

U- and 90 deg-bend were adopted as bend forming tests. In U-bend test, radius of punch was $6 \mathrm{~mm}$. In $90 \mathrm{deg}$-bend test, four kinds of punch radii were adopted. Radii of punch and die were the same size. Bending span is $70 \mathrm{~mm}$. After bend forming, the discrepancy between two skin steels was measured.

\section{Results}

Tensile properties of four types of damping steel sheets are almost the same (Table 1), because their configurations were the same. However, the $\mathrm{H}$ steel for high temperature use has the highest TSS (Fig. 2). Photograph 1 shows the appearance of U-bend test pieces. Bent test pieces of the $\mathrm{H}$ and $\mathrm{M}$ steels exhibit good shapes, but those of the L and LL steels exhibit bad. The discrepancy of skin steels are not observed in the $\mathrm{H}$ and $\mathrm{M}$ steels, but discrepancies are observed in the L and LL steels (Fig. 3).

Table 1. Mechanical properties and TSS.

\begin{tabular}{|c|c|c|c|c|c|c|}
\hline Steel & $\begin{array}{l}\text { Thickness } \\
(\mathrm{mm})\end{array}$ & $\begin{array}{c}Y S \\
(\mathrm{kgf} / \\
\left.\mathrm{mm}^{2}\right)\end{array}$ & $\begin{array}{c}T S \\
(\mathrm{kgf} / \\
\left.\mathrm{mm}^{2}\right)\end{array}$ & $\begin{array}{c}E l \\
(\%)\end{array}$ & $r$-value & $\begin{array}{l}\text { Ad.- } \\
\text { TSS } \\
(\mathrm{kgf} / \\
\left.\mathrm{cm}^{2}\right)\end{array}$ \\
\hline $\mathrm{H}$ & $0.7 / 0.1 / 0.7$ & 13 & 28 & 53 & 2.29 & 148 \\
\hline $\mathbf{M}$ & $0.7 / 0.1 / 0.7$ & 14 & 29 & 53 & 2.28 & 126 \\
\hline $\mathrm{L}$ & $0.7 / 0.1 / 0.7$ & 13 & 28 & 52 & 2.24 & 61 \\
\hline LL & $0.7 / 0.1 / 0.7$ & 14 & 28 & 52 & 2.28 & 6 \\
\hline Skin & 0.7 & 17 & 28 & 52 & 2.24 & - \\
\hline
\end{tabular}

JIS No. $5(G L=50 \mathrm{~mm})$

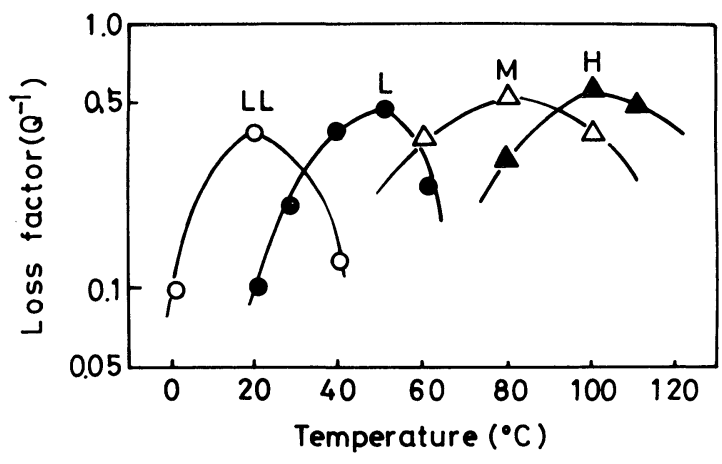

Fig. 2. Damping qualities of steels used.

* Presented to the 110th ISIJ Meeting, October 1985, S1578, at Niigata University in Niigata. Manuscript received on February 20, 1986; accepted in the final form on June 13, 1986. (C) 1986 ISIJ

** Iron and Steel Research Laboratories, Kawasaki Steel Corporation, Kawasaki-cho, Chiba 260. 


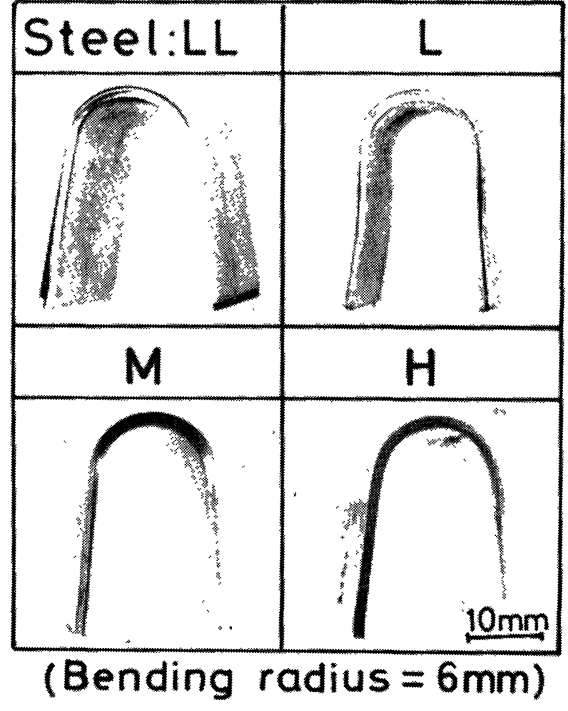

Photo. 1. Appearance of U-bend test pieces.

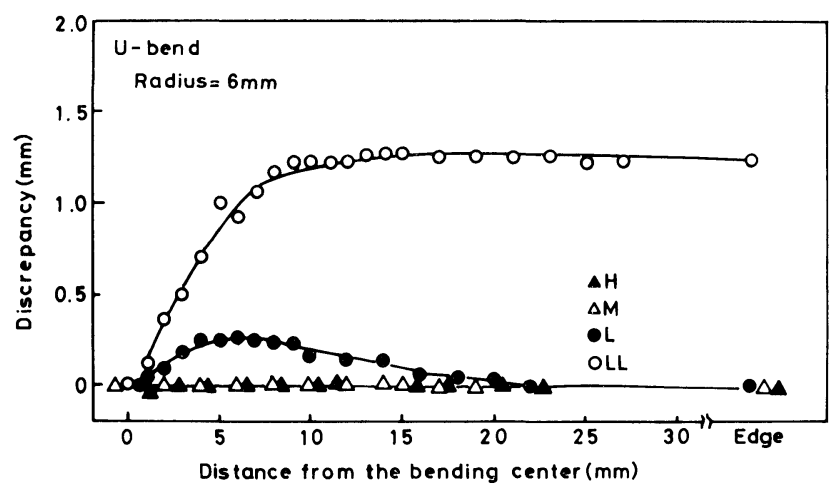

Fig. 3. Comparison with the discrepancy of damping steels in U-bend test.

Especially in the LL steel, the discrepancy does not reduce to $0 \mathrm{~mm}$, and the slip of edge is observed as shown in Photo. 1.

Photograph 2 shows appearance of $90 \mathrm{deg}$-bend test pieces. Bent or curved specimens as the shape of a flying sea gull2) were not be observed in all the test pieces. In case that the length of discrepancy is shorter than the bending span, generation of such defects will be suppressed.

Figure 4 shows the discrepancy in $90 \mathrm{deg}$-bend at the punch radius of $1.5 \mathrm{~mm}$. The $\mathrm{H}, \mathrm{M}$ and $\mathrm{L}$ steels show almost the same behaviors, and their discrepancies have maximum value about at $5 \mathrm{~mm}$ away from the bending center, and reduce to $0 \mathrm{~mm}$ at the portion of $15 \mathrm{~mm}$. But the discrepancy of the LL steel does not become $0 \mathrm{~mm}$ as in U-bend test. Relation between punch radii and angles of bent test pieces are shown in Fig. 5. Bend angle of the $\mathrm{H}$ and $M$ steels, and conventional steel sheets decrease with the decrement of punch radius, and the bend angles are almost the same as value in the conventional steel sheet. But the $\mathrm{L}$ and LL steels show different behaviors. In large punch radius, their bend angles exceed those of conventional steel sheets. In small punch radius, however, the bend angles are smaller.

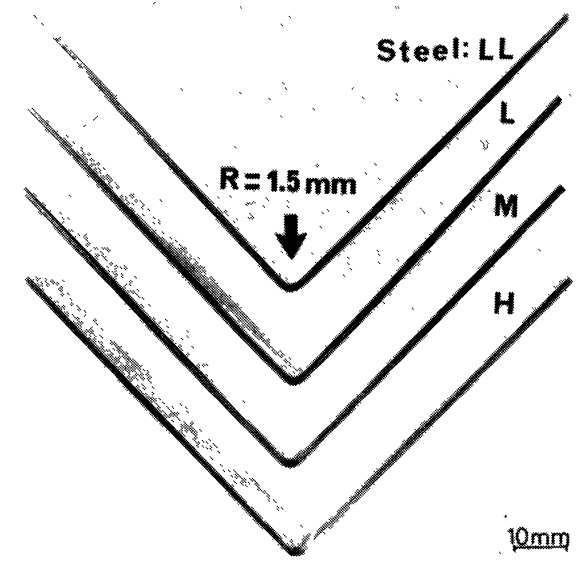

Photo. 2. Appearance of $90 \mathrm{deg}$-bend test pieces.

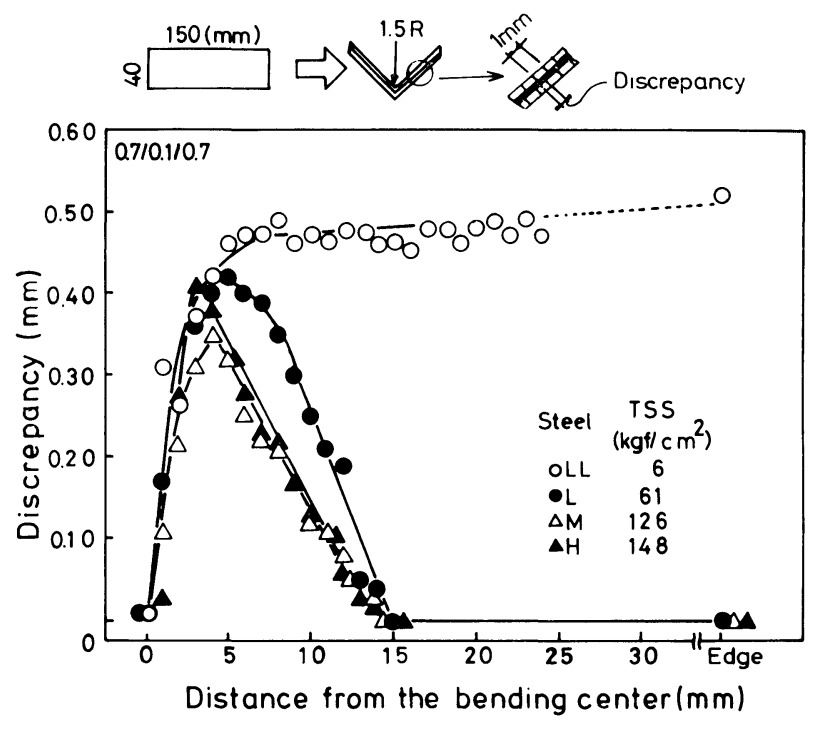

Fig. 4. Comparison with discrepancy of damping steels in 90 deg-bend test.

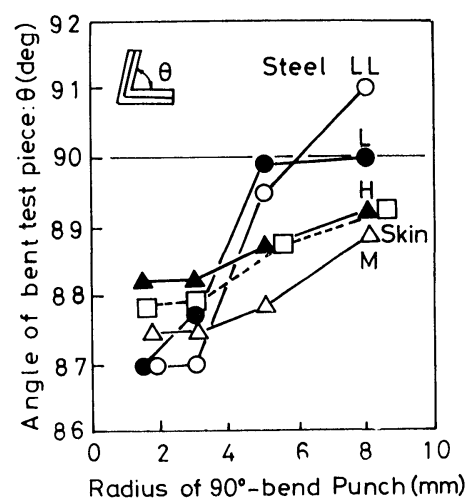

Fig. 5. Relation between punch radius and bent angle.

\section{Discussion}

The $\mathrm{H}$ and $\mathrm{M}$ damping steel sheets which have higher TSS than $120 \mathrm{kgf} / \mathrm{cm}^{2}$ exhibit good bendability. The higher TSS is, the larger the shearing resistant of visco-elastic material becomes. Therefore, in the damping steel sheet with high TSS the discrepancy hardly occurs. And the material which is hard at 
$R T$ has high flexural modulus of elasticity (FME). Consequently, the bendability of damping steel sheets depends on the FME. FME of these materials were measured by following the JIS K7203, which are listed in Table 2. The $\mathrm{H}$ and $\mathrm{M}$ steels have almost the same FME as the conventional steel sheet. Therefore, they exhibit similar behavior in $90 \mathrm{deg}$-bend test (Fig. 5). In addition, as they cannot be easily bent because of their high FME, discrepancies hardly occur. On the other hands, the LL and L steels having low FME can be easily bent, and discrepancies occur. Therefore, when the punch radius is small, namely, the bending load works concentratedly, the

Table 2. Flexural modulus of elasticity.

\begin{tabular}{|c|c|c|}
\hline $\begin{array}{c}\text { Configuration } \\
(\mathrm{mm})\end{array}$ & Steel & $\begin{array}{l}\text { Flexural modulus of } \\
\text { elasticity }\left(\mathrm{kgf} / \mathrm{mm}^{2}\right)\end{array}$ \\
\hline \multirow{4}{*}{$\begin{array}{l}0.7 / 0.1 / 0.7 \\
\left(\begin{array}{l}0.7: \text { steel } \\
0.1: \text { resin } \\
0.7: \text { steel }\end{array}\right)\end{array}$} & LL & $4400 \quad(21 \%)$ \\
\hline & $\mathrm{L}$ & $11460 \quad(55 \%)$ \\
\hline & M & $17760 \quad(85 \%)$ \\
\hline & $\mathrm{H}$ & $17840 \quad(85 \%)$ \\
\hline 1.5 & Gonventional & $21000(100 \%)$ \\
\hline
\end{tabular}

bend angles in the LL and L steels are smaller than those in the conventional steel sheet. But when the punch radius is large, the bend angles in the $\mathrm{LL}$ and $\mathrm{L}$ steels are larger than those in the conventional steel sheet. This is because that the bending load is dispersed due to their soft visco-elastic materials.

\section{Conclusion}

The effect of tensile shear strength (TSS) on the bendability of vibration-damping composite steel sheet was studied and following results are obtained:

(1) The bendability of damping composite steel sheet is closely concerned with TSS.

(2) Damping steel sheets which have higher TSS than $120 \mathrm{kgf} / \mathrm{cm}^{2}$ exhibit the good bendability.

(3) The lower TSS is, the worse the bendability is, namely, the discrepancy increases and the shape of bent test piece becomes bad.

\section{REFERENCES}

1) K. Ibonai: Elementary Plastics, Kogyo-Chousa-Kai Publ., Co., Ltd., Japan, (1978), 39.

2) M. Yoshida: J. Japan Soc. Tech. Plasticity, 26 (1985), 394. 